\begin{tabular}{|ccc}
\hline Sournals & $\begin{array}{c}\text { INTERNATIONAL JOURNAL OF } \\
\text { ORGANIZATIONAL LEADERSHIP }\end{array}$ & $\begin{array}{c}\text { INDUSTRIAL } \\
\text { MANAGEMENT } \\
\text { INSTITUTE }\end{array}$ \\
\hline \hline
\end{tabular}

\title{
The study of effective factors in the implementation of knowledge management: A case study of Hormozgan Steel Company
}

\author{
Tayeb Dehghani $^{*}$, Hesamaddin Kamalzadeh ${ }^{2}$ \\ ${ }^{1}$ Department of Management, College of Economic and Management, Bandar Abbas Branch, Islamic Azad \\ University, Bandar Abbas, Iran \\ ${ }^{2}$ Statistics and Information Technology Management, Hormozgan University of Medical Sciences (HUMS), \\ Bandar Abbas, Iran
}

\begin{tabular}{|c|c|}
\hline & Abstract \\
\hline $\begin{array}{l}\text { Keywords: } \\
\text { Success Factors of } \\
\text { Knowledge Management, } \\
\text { Culture, Structure, } \\
\text { Technology }\end{array}$ & $\begin{array}{l}\text { Today, one of the most important and valuable capitals in any organization is knowledge. } \\
\text { Rapid changes and high growth of knowledge and information lead any organization to } \\
\text { concentrate its effort on knowledge management to improve organizational abilities. } \\
\text { Therefore, studying effective factors in the implementation of knowledge management is of } \\
\text { great importance from cultural, structural, and technological aspects. This research is }\end{array}$ \\
\hline $\begin{array}{l}\text { Received } \\
26 \text { November } 2015\end{array}$ & $\begin{array}{l}\text { applicable in terms of goal and is a descriptive survey in terms of data collection. The } \\
\text { statistical population consisted of } 600 \text { official employees of Hormozgan Steel Company }\end{array}$ \\
\hline $\begin{array}{l}\text { Received in revised form } \\
3 \text { January } 2016\end{array}$ & $\begin{array}{l}\text { which } 234 \text { of them were selected as sample through stratified random sampling and } \\
\text { Cochran Formula. A questionnaire was used for data collection. The results indicated that }\end{array}$ \\
\hline $\begin{array}{l}\text { Accepted } \\
\text { 13 January } 2016\end{array}$ & $\begin{array}{l}\text { the mentioned company suffers from lack of implementation of knowledge management in } \\
\text { terms of culture aspect but in terms of two other aspects, i.e. technology and organizational } \\
\text { structure, knowledge management establishment is in good condition. }\end{array}$ \\
\hline
\end{tabular}

dehghani.tayeb@yahoo.com

(C)AIMI Journals

The main characteristic of smart organizations in the $21^{\text {st }}$ century is the emphasis on knowledge and information. Unlike previous organizations, today's organizations use advanced technology and require capturing, management, and utilization of knowledge and information to improve the performance, management, and pursuit of endless changes. Knowledge is a powerful tool which can bring changes to the world and promote innovation (Sobhani, 2008).

Knowledge is far beyond the information. With this perception, information is the result of organizing data in a significant way while knowledge is the result of interpreting information based on personal understanding influenced by the personality and characteristics of the 
individual. In other words, knowledge is the process of placing value from knowledge-based and intellectual property by the organization. In fact, knowledge is converted into a valuable resource and a competitive advantage for the organizations. Since every resource needs management, knowledge needs management too. Unfortunately, this value creating resource is ignored in most organizations due to the lack of a system which forces employees to document their experience and knowledge work on the one hand, and provide them with science related to professional jobs to fulfill different roles and responsibilities, on the other.

In fact, most employees, especially managers, use their old and outdated routines, experience, and knowledge and due to lack of knowledge management system, the emergence of knowledge is not possible and common (Chen \& Huang, 2007). Therefore, the gap in knowledge management as a value creating resource in the organization is noticeable more than ever, since today in modern economies the value of an organization unlike the old organizations is measured through intangible assets. Thus, the role of tangible assets in placing value for the organizations is faded. One of the intangible assets of today's organizations is their knowledge capitals. In this regard, some solutions have been offered to utilize the high value of knowledge and knowledge management is one of them. Knowledge management is considered as a modern approach to utilize and develop intangible assets of the organizations (Hossein Gholizadeh, Shabani Varaki, \& Mortazavi, 2005) and a series of processes to understand and apply strategic resource of knowledge in the organization. In other words, knowledge management is a structured approach which establishes routines to identify, evaluate and organize, and store and apply knowledge to meet the needs and goals of the organization. Therefore, knowledge management is the most important value creating and planned resource for the organization that determines competition in knowledge economy. According to Davenport and Prusak (1998), knowledge management helps to improve decision-making, do tasks well, enter markets easily, increase innovation, market share, utilization, service quality, coordination and learning ability, and adjust employees to the environment. It also helps to continuous personal learning and changes the organization into a learning organization. The most important pillar of knowledge management is its implementation and effectiveness; because any other related parts are introductions to achieve the objectives of knowledge management in the organizations. The benefits of applying knowledge management lead most organizations to implement this process.

However, knowledge management is a systematic issue and requires comprehensive attitude towards different organizational factors. In other words, successful implementation of knowledge management requires that different organizational factors such as organizational culture, organizational structure, technology, and human resources have special features and coherence (Norouzian, 2005). It is essential to mention that knowledge management places emphasis on three main topics of human being, structure and information, and communication technology. It can achieve its organizational objectives through creating proper structure and technological infrastructure in the organization, focusing on human being and training him as a knowledge worker, capturing, producing, and using knowledge resource (Afrazeh, 2004). Therefore, through providing coordination between all the effective components of implementing knowledge management, we can achieve knowledge management objectives, i.e. sharing knowledge, organizational knowledge retention, establishing relationships based on 
trust and cooperation, and converting into a knowledge-based organization to capture sustainable competitive advantage. Those factors that can affect successful implementation of knowledge management have been studied in previous researches (Liebowitz, 2001). However, there is no systematic study on specifying a coherent set of success factors (structure, technology and culture) in the implementation of knowledge management in large industries. Therefore, the present study attempts to investigate the effective factors in the implementation of knowledge management in Hormozgan Steel Company with a focus on organizational structure, information technology, and organizational culture in a coherent set.

\section{The Literature Review}

The history and development of knowledge management is not obvious because it has emerged from different fields. Many researchers such as Blackman, Kennedy, and Ritchie (2011), Gunasekarany and Ngai (2007), Hemsley and Mason (2013), Hlupic, Pouloudi, and Rzevski (2002), Lwoga, Ngulube, and Stilwell (2010), Meier (2011), Pandey (2014), Stewart and Waddell (2008), Storey and Kahn (2010), and Zhao and Ordóñez de Pablos (2011) have focused their attention on knowledge management. A number of management theorists like Peter Drucker, Paul Stresemann, Peter Singe, etc. have played a role in developing knowledge management theoretically. As cited in Abbaszadeh Shahri and Rajablou (2009), Drucker and Strassman have emphasized on the increasing importance of information and explicit knowledge as important organizational resources and Peter Singe have focused on learning organizations as the cultural dimension of knowledge management. In the early 1990, knowledge management seriously entered topics of organization. However, discussion and negotiation on knowledge started form a long time ago. In 1965, Marshall declared that a considerable part of capital involves knowledge. He also believes that knowledge is the most strong and influential engine of generation, so the organizations should growingly focus on its management (Khanifar, Ataei, Maleki, Abdolhosseini, \& Emami, 2013). A number of previous internal and external researches on this topic are reviewed as following.

In a research under the title of "Establishing a knowledge management programme for competitive advantage in an enterprise" by Ndlela and Du Toit (2001), the enablers and barriers to implement a knowledge management programme and whether it is seen as a source for competitive advantage and proving that how competitive advantage is guaranteed through knowledge management establishment were determined. This empirical survey was conducted in the Eskom Transmission Group, Johannesburg, South Africa. The results indicated that knowledge management has a positive impact on competitive advantage.

Knowledge management practices in a study by Zack, Mckeen, and Singh (2009) were found to be directly related to organizational performance which, in turn, was directly related to financial performance. In the study, conducted in the field of knowledge management in public organizations, Syed-Ikhsan and Rowland (2004) examined the relationship between organizational components (organizational culture, technology and human resources, and political orientations) and ability of knowledge creation in Malaysian Ministry of Development and Entrepreneurship. Results showed that there is an important relationship between some of these variables and knowledge management. In another research conducted by Zhou (2004), the differences between knowledge management practices and intellectual capital in private 
and public sector in terms of (organizational culture, organizational structure and information technology) in Australia were indicated. Findings revealed that public sector respondents in Australia had a less developed understanding in knowledge management and intellectual capital as compared to the private sector respondents. Moreover, knowledge management initiatives were not frequently addressed at the strategic level; employees were not much trained and developed, few measurement systems were developed, and almost no incentive and reward measures were constructed. In addition, public sector respondents were less confident about the roles of organizational culture, organizational structure, and information technology in knowledge management in their organization (Zhou, 2004).

Saedi and Nadalipour (2006) attempted to present an implementation model of knowledge management in Iran Khodro Company which has been developed based on learning and source-centered view on the grounds of information technology. This model explained the stages of knowledge management development and the roles of major factors like learning processes, organizational resources, and information technology in the implementation of model.

Among various models, Iran Khodro Company has chosen United Nations electronic government model and its five stages to implement knowledge management of information technology. These stages include emerging presence, enhanced presence, interactive presence, transactional presence, and networked presence (Saedi, \& Nadalipour, 2006). In his research through choosing organizational factors of culture, structure and technology form various factors in relation to two main practices of management, i.e. knowledge creation and knowledge transfer. Askari (2005) concluded that there was a significant relationship between these factors and knowledge management and to establish knowledge management successfully, they must be considered and analyzed. Askari (2008) conducted a research with the aim of examining the possibility of knowledge management establishment in Mazandaran university centers and concluded that from the viewpoint of educational and executive administrators, the existing information technology have prepared the grounds for knowledge management establishment. The existing organizational culture has impact on knowledge management establishment. The role of human resources and the impact of organizational learning on knowledge management establishment have been confirmed.

\section{The Study}

The model of research was developed according to the models in theoretical foundations in the field of knowledge management. These models consist of Afrazeh's (2004) three dimensions of knowledge management, the model of knowledge management structure of Lee and Hong (2002), and the factors of knowledge success of Lee and Choi (2003) which include culture (trust, cooperation, and learning), structure (decentralized and multiple relationship), and technology (information technology). Finally, the conceptual model of knowledge management with the emphasis on key success factors of Jafari, Seyed Ameri, Arzeh, and Moharramzadeh (2008) was studied as well.

According to the mentioned models and hypotheses, the conceptual model of research is illustrated in Figure 1. 


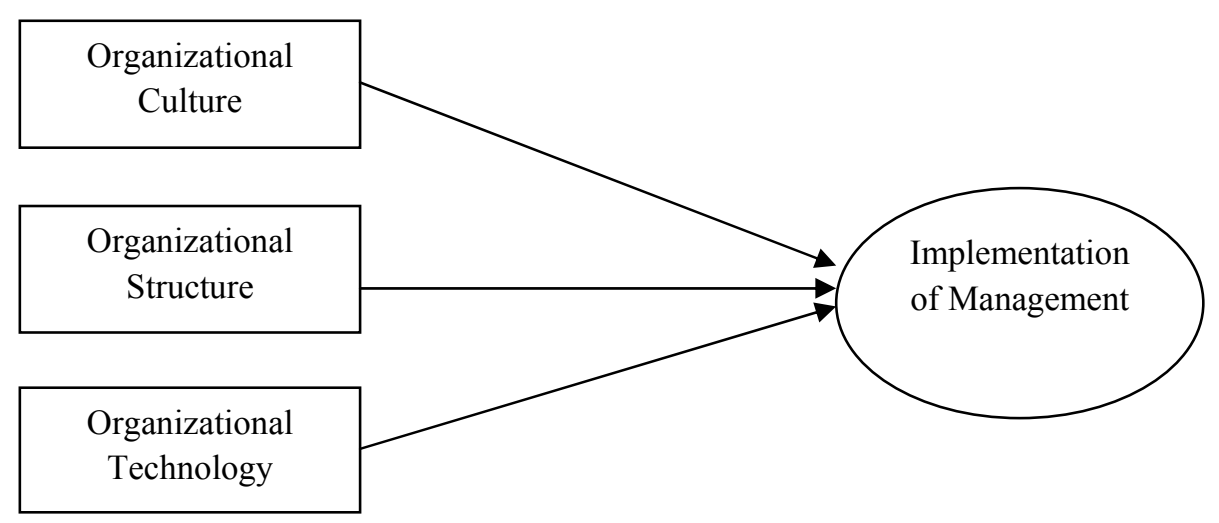

Figure 1. The conceptual model of research with the emphasis on success factors

\section{Research Hypotheses}

1. Organizational culture has significant impact on the implementation of knowledge management.

2. Organizational structure has significant impact on the implementation of knowledge management.

3. Organizational technology has significant impact on the implementation of knowledge management.

\section{Method}

The present study is a descriptive survey in terms of data collection, since it tests hypotheses, seeks answers to the questions, and investigates the effective factors in the implementation of knowledge management. In terms of goal, the current research is applicable, because it aimed to solve a particular problem in the society. The unit of analysis refers to the aggregate level of the data collected in the following analyses which determine the nature of research question. In the present study, the unit of analysis is the individuals. Since we study the collected data from the viewpoint of every individual, we consider them as the source of data.

Statistical population refers to a complete set of items that share at least one property in common. In this research, the statistical population consists of 600 official employees of Hormozgan Steel Company. The sample included 73 Support Personnel and 35 Production Personnel. We employed stratified random sampling.

Therefore, in this method, the questionnaires are distributed among all the categories of the population proportionally. Data collection tools of this research are standard which were designed by Lawson in 2003 for evaluating knowledge base and by Walton for evaluating the quality of work life. The reliability of questionnaires was measured through Cronbach's alpha and SPSS software. The reliability coefficient is equal to $89 \%$. Moreover, to analyze the obtained data, inferential statistics (regression testing through the technique of structural equation with LISREL software, version 8.5) were used.

\section{Confirmatory Factor Analysis of Research Variables}

In inferential analysis, before testing the hypotheses, we should test the validity through confirmatory factor analysis test. In fitness test, in confirmatory and path analysis, the index of RMSEA or the root mean square error of approximation is less than $8 \%$, and GFH, CFL, IFI, 
and NNFI are more than $90 \%$. If the T-value of variables is greater than 1.96 and lower than -1.96 , the model has a good fit. The abbreviations of latent and observed variables are presented in Table 1 before demonstrating the output of the software.

Table 1

Abbreviations of Model Variables

\begin{tabular}{lc}
\hline Index & Abbreviations \\
\hline Organizational Culture & Culture \\
Organizational Structure & Structure \\
Organizational Technology & Technology \\
Implementation of Knowledge Management & KM \\
\hline
\end{tabular}

The results of factor analysis using Maximum Likelihood and load factors of each question in factors are shown in Table 2.

Table 2

Overall measurement model resulting from confirmatory factor analysis

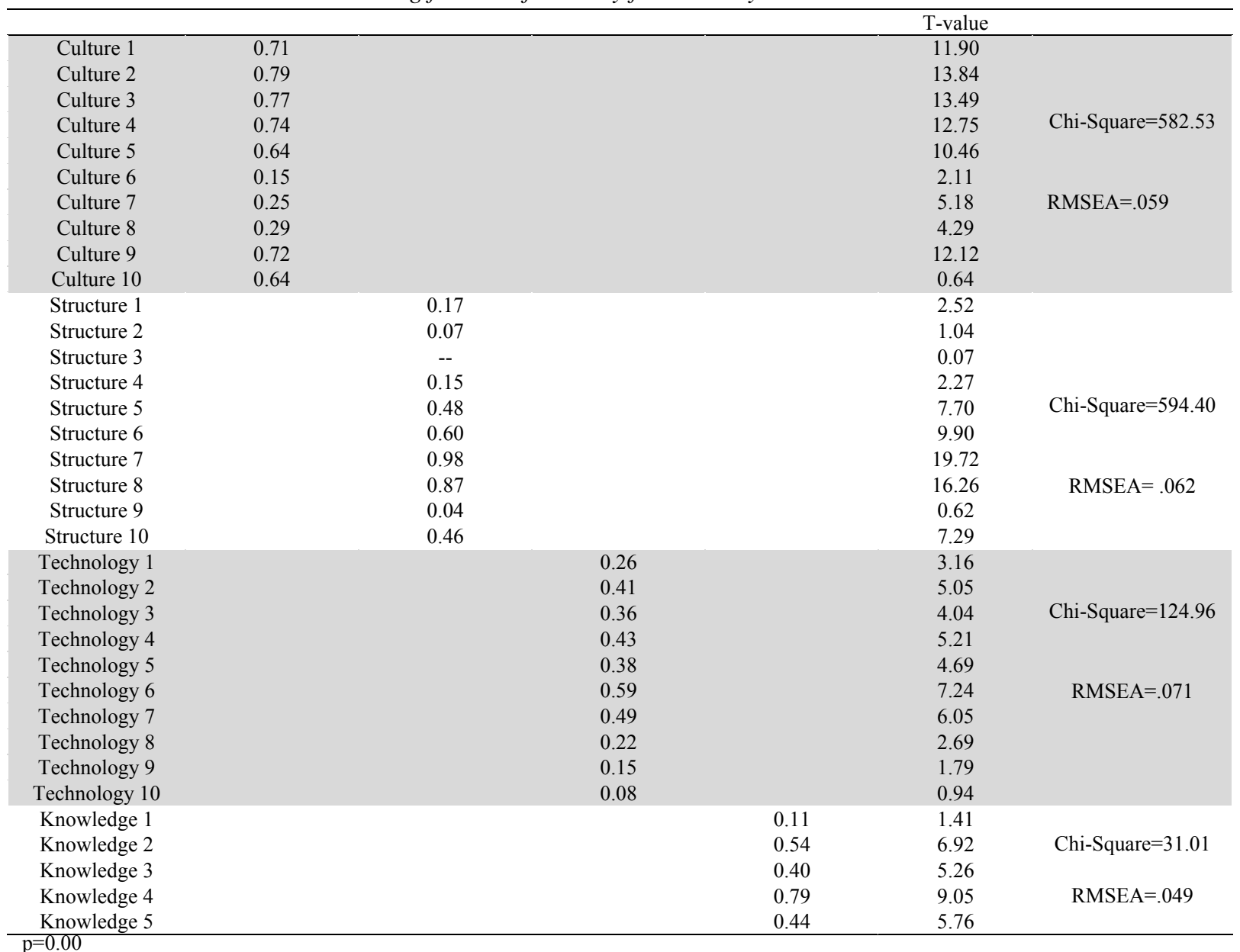

The threshold amount was considered 0.4; to this end, the questions that had lower load factors were deleted and then removed from the analysis. RMSE values of all three factors were less than three, so, they show the fitness of models. In the factor relating to culture, questions 7 and 8; in the structure factor, questions 1, 2, 3, 4, and 9; in the technology factor, 
questions $1,3,5,8,9$, and 10; and in knowledge management factor, question 1 were removed from the analysis and the total amount of variance were equal to 53.46.

\section{Investigating the Normality of Variables Distribution}

Before testing the relationships between variables, we investigate the normality of variables. One of the methods of investigating the normality of variable distribution is KolmogorovSmirnov Test. The results of this test are presented in Table 3.

Table 3

Normal Distribution of Variables

\begin{tabular}{lcr}
\hline Components & Kolmogorov-Smirnov & Significance \\
\hline Organizational Culture & 2.766 & 0.000 \\
Organizational Structure & 3.359 & 0.000 \\
Organizational Technology & 1.606 & 0.000 \\
Implementation of Knowledge Management & 2.707 & 0.000 \\
\hline
\end{tabular}

The results of this test indicated that the significance level of research variables was less than 0.05 . According to central limit theorem, the results of this questionnaire were normal through the SPSS software. Therefore, the null hypothesis i.e. the normality of variables is confirmed.

Figure 2 and Figure 3 exhibit measuring the general model and the results of hypotheses in the standard mode and measuring the general model and the results of hypotheses in the significance mode, respectively.

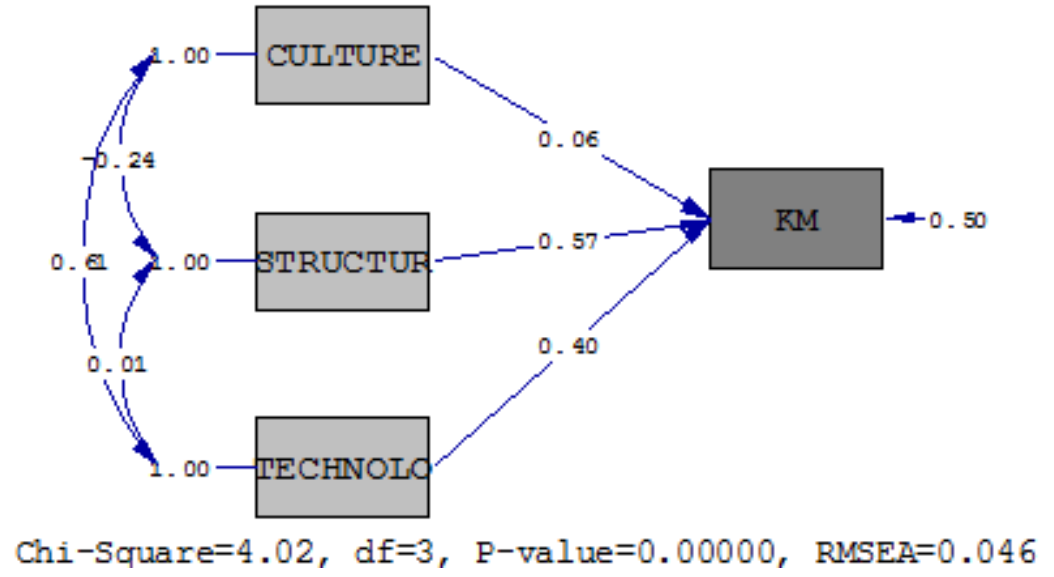

Figure 2. Measuring the general model and the results of hypotheses in the standard mode 


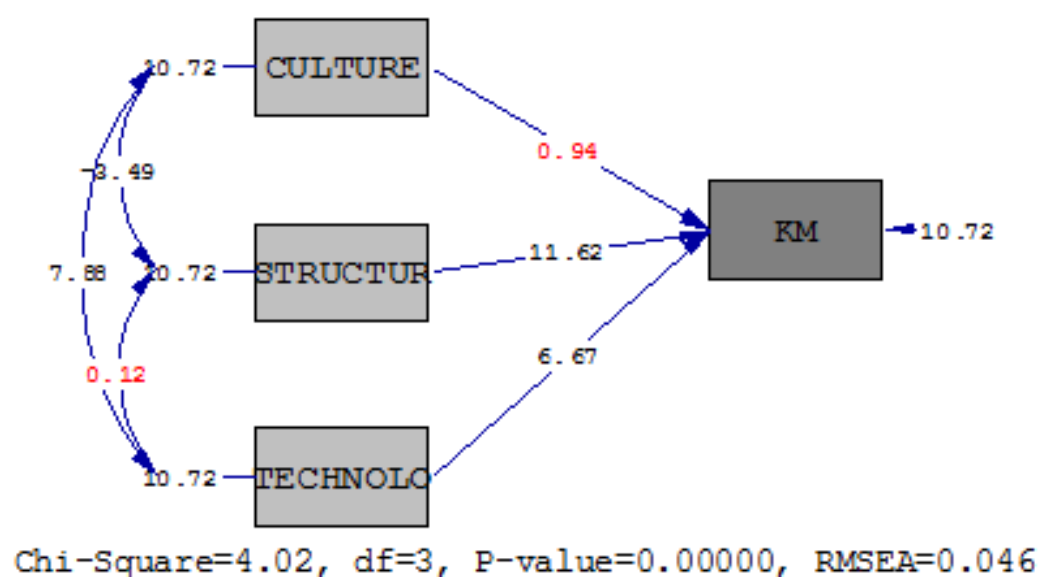

Figure 3. Measuring the general model and the results of hypotheses in the significance mode

Table 4 shows the indexes of fitness of research conceptual model.

Table 4

The Indexes of Fitness of Research Conceptual Model

\begin{tabular}{lllllll}
\hline $\mathrm{X}^{2} / \mathrm{df}$ & RMSEA & RMR & GFI & CFI & NNFI & IFI \\
\hline 1.98 & 0.071 & 0.039 & 0.95 & 0.94 & 0.94 & 0.93 \\
\hline
\end{tabular}

\section{Results}

Since the distribution was normal (the results of Kolmogorov-Smirnov test) the correlation of variables is tested through LISREL software. To investigate the causal relationship between the dependent and independent variables and to confirm the model, path analysis was conducted through LISREL version 8.5. The results of LISREL output indicated that $\mathrm{k}^{2}$ degrees of freedom $\left(\mathrm{k}^{2} / \mathrm{df}\right)$ is less than 3 and other indexes of fitness confirm the fitting model. Table 5 indicates the significance coefficient and the results of hypotheses.

Table 5

The Significance Coefficient and the Results of Hypotheses

\begin{tabular}{lccc}
\hline Hypotheses & Standard & Significance & Result \\
\hline $\begin{array}{l}\text { Organizational culture has a positive and significance impact on the } \\
\text { implementation of knowledge management }\end{array}$ & 0.06 & 0.94 & Rejected \\
$\begin{array}{l}\text { Organizational structure has a positive and significance impact on the } \\
\text { implementation of knowledge management }\end{array}$ & 0.57 & 11.62 & Confirmed \\
$\begin{array}{l}\text { Organizational technology has a positive and significance impact on } \\
\text { the implementation of knowledge management }\end{array}$ & 0.40 & 6.67 & Confirmed \\
\hline
\end{tabular}

In the first hypothesis, it was claimed that organizational culture has a significant impact on the implementation of knowledge management. Statistical analysis indicated that the significance path number between these two variables is 0.94 and since this value is less than 1.96; to this end, this hypothesis is rejected.

In the second hypothesis, it was stated that organizational structure has a significant impact on the implementation of knowledge management. Statistical analysis demonstrated that the significance path number between these two variables is 11.62 and since this value is greater than 1.96, this hypothesis is confirmed. On the other hand, as the obtained significance number 
is positive, this impact is direct. The level of effectiveness of two variables is 0.57 which indicates that a unit of change in organizational structure changed 0.57 units in the implementation of knowledge management aligned with organizational structure.

In the third hypothesis, it was mentioned that organizational technology has a significant impact on the implementation of knowledge management. Statistical analysis indicated that the significance path number between these two variables is 6.67 and since this value is greater than 1.96, this hypothesis is confirmed. On the other hand, as the obtained significance number is positive, this impact is direct. The level of effectiveness of two variables is 0.40 which indicates that a unit of change in organizational technology changed 0.40 units in the implementation of knowledge management aligned with organizational technology.

\section{Discussion and Conclusion}

Although establishing knowledge management in public and private organizations makes great achievement, most organizations neglect it and delay its establishment. In the second part of the research, through investigating the previous studies on knowledge management, it was confirmed that organizational factors of culture, structure and technology as the key factors of knowledge success could be considered as the leading factors in knowledge management establishment. Therefore, in this research, it was attempted to investigate hypotheses in order to establish knowledge management. Analyzing the findings of research questions indicated that from the viewpoint of studied population, the implementation of knowledge management from two dimensions of organizational structure and information and communication technology as the success factors of knowledge management in that company is available. In fact, the existing organizational culture does not have the necessary conditions for successfully establishing the knowledge management. Thus, to use the achievements of knowledge management and its advantages, culture-building practices must be initiated in Hormozgan Steel Company. Moreover, implementation of knowledge management must be put into practice. Comparing the different dimensions of the knowledge management implementation in the aforementioned company indicates that organizational structure is in good condition. Since it has the highest mean rank and organizational technology has the second mean rank; therefore, the results of the present research in the mentioned company contribute to a clear perception of three dimensions in the establishment of knowledge management. Moreover, Considering the priorities of these dimensions, paying attention to the balanced maturity of them, using effective strategic plans to create them through various tools, taking major steps to implement adopted strategies in this regard according to the multiple indexes of three dimensions make it possible to establish knowledge management. Following this, it can be stated that Hormozgan Steel Company and other organizations or companies must reinforce those three components to establish knowledge management.

According to the results of data analysis, it can be confirmed that there is coordination between the results of the present study and the results of previous studies on organizational culture, structure and information, and communication technology which are success factors in knowledge management establishment. However, the difference between this study and other studies is the comprehensiveness of dimensions and components of conceptual model; since in the present research, according to researchers, the conditions of knowledge management 
establishment are three dimensions and six components. In addition, prior to this study, there was no comprehensive study on examining the possibility of knowledge management.

\section{References}

Abbaszadeh Shahri, A., \& Rajablou, R. (2009). Knowledge-based management and its application in exploration and production companies. Journal of Exploration \& Production of Oil and Gas, 61, 9-10.

Afrazeh, A. (2004). Knowledge maps. Paper presented at the First International Conference on Information and Communication Technology Management, Tehran, Iran.

Askari, N. (2005). An investigation into the relationship between organizational factors (structure, culture and technology) of Ministry of Labour and Social Affairs and knowledge management strategy (Unpublished master's thesis). Tehran University, Iran.

Askari, M. (2008). Examining the possibility of knowledge management establishment: A case study of Mazandaran university centers. Quarterly Journal of Faculty of Economics \& Administrative Sciences of Mazandaran University, 17(3), 121-139.

Blackman, D., Kennedy, M., \& Ritchie, B. (2011). Knowledge management: The missing link in DMO crisis management? Current Issues in Tourism, 14(4), 337-354.

Chen, Ch. J., \& Huang, J. W. (2007). How organizational climate and structure affect knowledge management—The social interaction perspective. International Journal of Information Management, 27(2), 104-118.

Davenport, D. T., \& Prusak, L. (1998). Working knowledge: How organizations manage what they know. Boston: Harvard Business School Press.

Gunasekarany, A. \& Ngai, E. W. T. (2007). Knowledge management in 21st century manufacturing. International Journal of Production Research, 45(11), 2391-2418.

Hemsley, J., \& Mason, R. M. (2013). Knowledge and knowledge management in the school media age. Journal of Organizational Computing \& Electronic Commerce, 23, 138-167.

Hlupic, A., Pouloudi, A., \& Rzevski, G. (2002). Towards an integrated approach to knowledge management: 'Hard', 'Soft' and 'Abstract' Issues. Knowledge \& Process Management, 9(2), 90-102.

Hossein Gholizadeh R., Shabani Varaki, B., \& Mortazavi, S. (2005). Relation between organizational culture and knowledge management in higher education: A case of Ferdowsi University of Mashhad. Studies in Education \& Psychology, 6(1), 527.

Jafari, S., Seyed Ameri, M. H., Arzeh, K., \& Moharramzadeh, M. (2008). An investigation of organizational factors (structure and technology) of Physical Education Organization through the strategy of knowledge management. Journal of Research on Sport Sciences, 20(3), 157-172.

Khanifar, H., Ataei, F., Maleki, H., Abdolhosseini, B., \& Emami, M. (2013). The study of the relation between organizational justice and knowledge management. International Business Management, 59, 15379-15382.

Lawson, S. (2003). Examining the relationship between organizational culture and knowledge management (Unpublished doctoral dissertation). Nova Southeastern University, United States.

Lee, H., \& Choi, B. (2003). Knowledge management enablers, and organizational performance: An integrative view and empirical examination. Journal of Management Information Systems, 20(1), 179-228.

Lee, S., M., \& Hong, S. (2002). An enterprise-wide knowledge management system infrastructure. Industrial Management \& Data System, 102(1), 17-25

Liebowitz, J. (2001). Knowledge management: Learning from knowledge engineering. Florida, United States: CRC Press.

Lwoga, E. T., Ngulube, P., \& Stilwell, C. (2010). Managing indigenous knowledge for sustainable agricultural development in developing countries: Knowledge management approaches in the social context. The International Information \& Library Review, 42(3), 174-185.

Meier, M. (2011). Knowledge management in strategic alliances: A review of empirical evidence. International Journal of Management Reviews, 13(1), 1-23.

Ndlela, L. T., \& Du Toit, A. S. A. (2001). Establishing a knowledge management programe for competitive advantage in an enterprise. International Journal of Information Management, 21(2), 151-165.

Norouzian, M. (2005). Knowledge management application in public sector. Tadbir, 156, 24-29.

Pandey, K. N. (2014). Knowledge management processes: A case study of NTPC and POWERGRID. Global Business Review, 15(1), 151-174.

Saedi, M., \& Nadalipour, H. (2006). Implementation model of knowledge management in Iran Khodro Company based on learning and source-centered view on the company on the grounds of information technology. Paper presented at the Second International Conference on Information Technology and Development Management, Tehran, Iran.

Sobhani, A. (2008). Information technology and knowledge management. Paper presented at the Third International Management Conference, Tehran, Iran.

Stewart, D., \& Waddell, D. (2008). Knowledge management: The fundamental component for delivery of quality. Total Quality Management, 19(9), 987-996.

Storey, C., \& Kahn, K. B. (2010). The role of knowledge management strategies and task knowledge in stimulating service innovation. Journal of Service Research, 13(4) 397-410.

Syed-Ikhsan, S. O. S., \& Rowland, F. (2004). Benchmarking knowledge management in a public organization in Malaysia. Benchmarking: An International Journal, 11(3), 238-266.

Zack, M. H., Mckeen, J. D., \& Singh, S. (2009). Knowledge management and organizational performance: An exploratory survey. Journal of Knowledge Management, 13(6), 392-409. 
Zhou, A. Z. (2004). Managing knowledge strategically: A comparison of managers' perceptions between the private and public sector in Australia. Journal of Information \& Knowledge Management, 3(3), 213-222.

Zhao, J., \& Ordóñez de Pablos, P. (2011). Regional knowledge management: the perspective of management theory. Behaviour \& Information Technology, 30(1), 39-49. 